\title{
Postmortem demonstration of intrapulmonary arteriovenous shunting
}

\author{
M J Wilkinson, D G Fagan
}

\begin{abstract}
The measurement of the pressure required to drive a $2 \%$ solution of gelatin across the pulmonary vascular bed of a group of 49 infants dying suddenly at less than 44 weeks' postnatal age, has shown the presence of low pressure arteriovenous shunting in $\mathbf{3 0}$ cases (61\%). Injection of polymethylmethacrylate beads in three cases has demonstrated that the vessels that form the shunts are up to $\mathbf{6 0}$ $\mu \mathrm{m}$ in diameter. The presence of vessels allowing shunting at pressures as low as 0.1 $\mathrm{kPa}\left(1 \mathrm{~cm} \mathrm{H}_{2} \mathrm{O}\right)$ could severely compromise the gas exchange function of the lung.
\end{abstract}

The syndrome of prolonged expirational apnoea is well recognised. ${ }^{1}$ In this syndrome children may rapidly develop very profound arterial hypoxaemia after relatively short periods of apnoea. $^{2}$ It has been postulated that this hypoxaemia is due to the sudden development of intrapulmonary arteriovenous shunting.

It is a commonly held belief that there is no anatomical basis for the shunting, but it is observed at ages by which the foramen ovale and the ductus arteriosus have closed. In live children exhibiting shunting of this type echocardiography has been used to demonstrate the absence of intracardiac shunts and that the ductus arteriosus is closed. ${ }^{3}$ Subsequent necropsy confirmed the closure of the ductus but the shunting remained unexplained.

The belief that there is no anatomical basis for the shunting appears to be based on the work of Hislop and Reid who described the development and anatomy of the pulmonary vasculature in a group of children with ages ranging between 3 days and 11 years but found no evidence of shunts. ${ }^{4}$ Their method outlined the pulmonary vessels by injection of a concentrated solution of gelatin (25\%) into the pulmonary artery of previously frozen lungs. The vessels were assessed on radiographs of the lung with limited histology. Vessels down to $15 \mu \mathrm{m}$ in diameter were filled with the mixture but no gelatin was seen in the pulmonary capillaries or in the pulmonary veins.

We used a similar technique to Hislop and Reid with a less concentrated solution and lower injection pressure in fresh lungs and found that in some cases the injection mixture flowed freely from the pulmonary vein. Histologically gelatin can be seen in the pulmonary veins, occasional capillaries, and airspaces.

Material and methods

Since 1985 we have been injecting the pulmon- ary arteries with a solution of gelatin to study the development of the pulmonary vasculature. In some cases we noted that the gelatin flowed freely from the pulmonary vein, so we began to measure the pressure required. The fresh lungs of 49 infants up to 44 weeks' old, whose deaths had been referred to the coroner, were used in this study. All the infants had died to some degree unexpectedly both in hospital and at home. The Emery system of classifying infant death was used. ${ }^{5}$ In this class $A$ are infants with a known fatal illness who are expected to die; class $B$ are infants with a curable but potentially life threatening illness that may be treated, class $\mathrm{C}$ are infants with antemortem or postmortem evidence of minor illness who die unexpectedly, and class D are infants with little or no postmortem evidence of disease to explain death. It must be emphasised that the classification is based on findings at necropsy and on examination of subsequent histology. Thus significant but unexpected findings are classified as for the disease, not the state of apparent wellbeing of the infant before death.

The thoracic contents were removed intact, the right lung isolated, and the right pulmonary artery cannulated. A $50 \mathrm{ml}$ syringe was connected by a three way tap to the cannula, with the third arm connected to a water manometer. A mixture of barium sulphate and $2 \%$ gelatin was injected through the cannula into the artery. The pressure required to obtain a free flow of the mixture from the pulmonary vein was noted.

In three cases one lobe of the left lung was cannulated and a separate gelatin mixture containing polymethylmethacrylate beads with diameters up to $64 \mu \mathrm{m}$ in diameter injected. The mixture passing across the pulmonary vascular bed was collected from the left atrium thereby ensuring that the outflow sample was not contaminated by material from the inflow sample. The size of the beads was measured using a Kontron videoplan image analyser.

In two cases the right lung was injected immediately after the necropsy, the left was kept for either 24 or 36 hours at $4^{\circ} \mathrm{C}$ before

Results of pressure measurements in 49 cases studied (pressure in $k P a$ )

\begin{tabular}{lclll}
\hline Emery grade $^{5}$ & \multicolumn{5}{c}{ Pressure/No of cases showing shunting } \\
\cline { 2 - 5 } & $\leqslant 0 \cdot 5$ & $0 \cdot 6-1 \cdot 0$ & $1 \cdot 1-2 \cdot 0$ & $>2 \cdot 0$ \\
\hline A & 3 & 0 & 2 & 1 \\
B & 4 & 3 & 1 & 2 \\
D & 10 & 6 & 6 & 5 \\
D & 0 & 4 & 2 & 0 \\
\hline
\end{tabular}

Normal pulmonary diastolic pressure $=7.5 \mathrm{mmHg}(1 \mathrm{kPa}$ or $10 \mathrm{~cm} \mathrm{H}_{2} \mathrm{O}$ ). 
injection. No significant alteration in shunt pressure was observed.

In two cases with very low shunt pressures numerous serial sections were cut. No unequivocal abnormal shunt vessels were identified and it was hard to trace continuity between arteries and veins in vessels of the required size.

\section{Results}

In the six grade $\mathrm{A}$ cases the causes of death included: trauma, pneumonia, bronchopulmonary dysplasia, and congenital heart disease. In the 10 grade $B$ cases they included: mening-

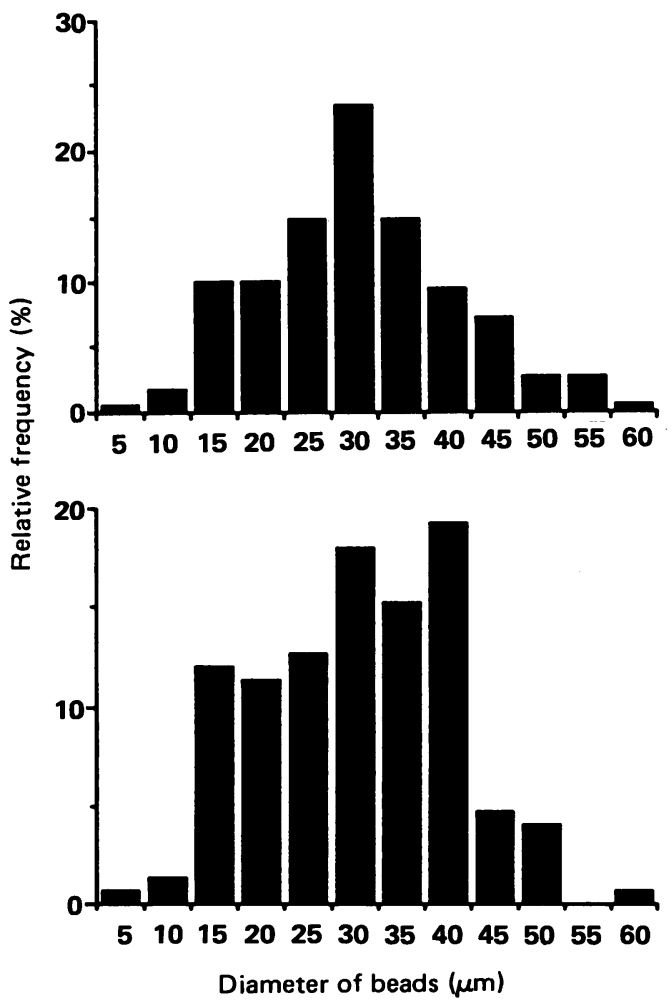

Figure 1 Graph showing the relative frequency diameter of beads in the injected material (upper graph) and in the material collected from the left atrium, (lower graph) in case 3.

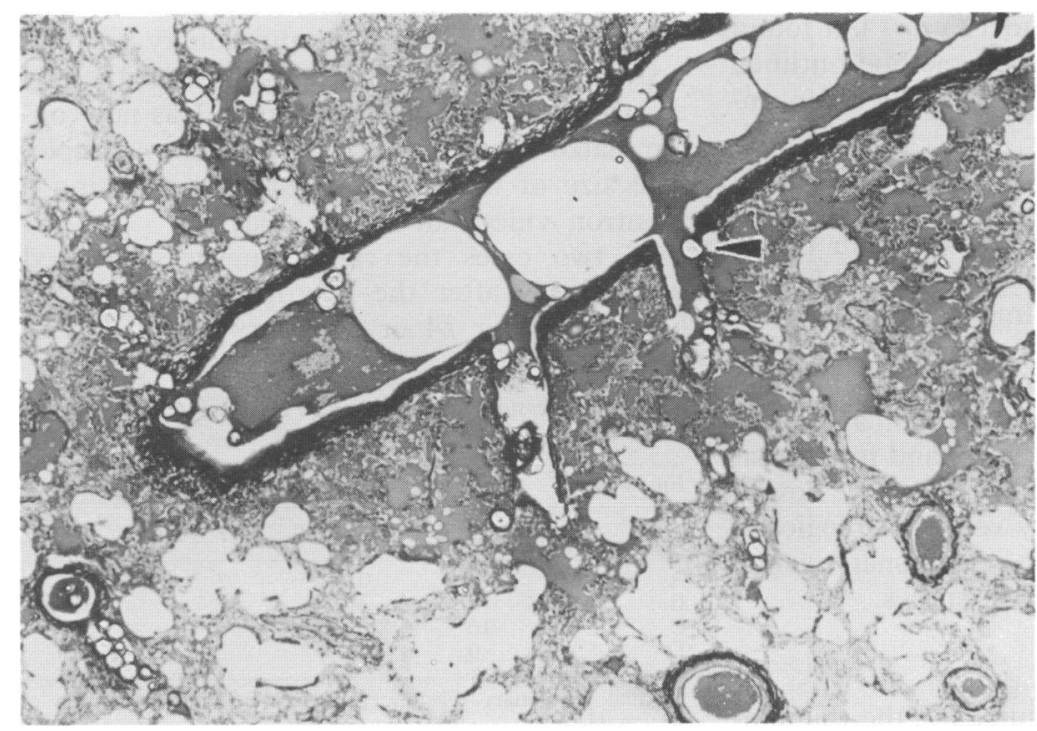

ococcal infection, tracheobronchitis, and viral and bacterial pneumonias. In the 27 grade $\mathrm{C}$ cases there were mostly early infective changes in the lung frequently with positive viral and bacterial cultures. In the six grade D cases only minimal findings were made at necropsy. These cases often had with positive viral and bacterial cultures with major organisms.

The perfusion pressure and some details of the patients studied are detailed in the table. Thirty of the cases showed perfusion at $<1 \mathrm{kPa}$ $\left(<10 \mathrm{~cm} \mathrm{H} \mathrm{H}_{2} \mathrm{O}\right)$ with 19 at $>1 \mathrm{kPa}$.

The presence of shunting vessels has been inferred in those cases where the perfusion pressure was $<1 \mathrm{kPa}$ (approximately equal to pulmonary diastolic pressure). In some of the cases there were only minimal findings at necropsy.

The group of cases in which shunting vessels were shown has a very similar distribution of Emery class to the group in which shunting vessels were not shown. The three cases in which beads were also injected are indicated with an asterisk. Measurement of the beads in the effluent is shown in fig 1. Large numbers of beads up to $40 \mu \mathrm{m}$ in diameter pass through with occasional beads up to $55 \mu \mathrm{m}$ in diameter. Histological assessment of the lungs showed the presence of gelatin mixture in small intra-acinar non-muscularised and muscularised vessels. Figure 2 shows beads up to $50 \mu \mathrm{m}$ in diameter in venules and veins.

\section{Discussion}

The initial impression of a group of cases in which venous return occurs at a low injection pressure is confirmed by the data in which the perfusion pressure was measured. The normal pulmonary diastolic blood pressure is around $7.5 \mathrm{~mm} \mathrm{Hg}\left(1 \mathrm{kPa}\right.$ or $\left.10 \mathrm{~cm} \mathrm{H}_{2} \mathrm{O}\right)$. In 30 of our 49 cases the flow occurred at a pressure less than this. In life this would allow the flow of blood across the lung at a very rapid rate even during diastole. These findings clearly demonstrate the presence of intrapulmonary arteriovenous shunting.

The injection of beads and measurement of the diameter of those beads able to pass through the vascular bed confirms that shunting vessels are present. The maximum diameter of the beads in the effluent from case 3 is about $55 \mu \mathrm{m}$ but the size that significant numbers pass through is about $40 \mu \mathrm{m}$. The diameter of the normal pulmonary capillary is less than that of a red cell $(7 \mu \mathrm{m}){ }^{6}$ It is inconceivable that a pulmonary capillary will stretch to increase its diameter by $2000 \%$. Thus shunting vessels must be present in the lungs of these children.

Histological assessment of the lungs showed that although gelatin is present in the pulmonary veins, most of the capillaries are ruptured and the gelatin has passed into the airspaces. Beads are seen in the pulmonary veins, but not

Figure 2 Section of lung showing beads up to $50 \mu \mathrm{m}$ in diameter in veins and venules (arrowed). The section is $10 \mu \mathrm{m}$ thick, illumination has been adjusted to give interference that highlights beads. (Elastin picro-sirius red $\times 62$.) 
in the capillaries and only rarely in the airspaces. Thus the histological findings support the observation that there are arteriovenous shunting vessels in the lung.

The demonstration of these arteriovenous shunts appears to be in conflict with the finding of Hislop and Reid. ${ }^{4}$ However, there are significant differences between our methods and theirs. Hislop and Reid studied lungs from 18 cases collected over a five year period; all the children were defined as normal with death due to accident. The ages ranged from 3 days to 11 years; although the ages of the cases is not stated, it is unlikely that there was a large number of infants under the age of 8 months. In their study, after removal from the body, the lungs were kept at a temperature of $-2^{\circ} \mathrm{C}$ for an undefined period, and then thawed for 48 hours at room temperature before study. The lungs we have studied came from children dying of natural causes. Necropsies were performed within 24 hours and the injection performed as part of this on the fresh lung.

Hislop and Reid used a concentrated solution of gelatin $(25 \%)$ whereas we used a relatively weak concentration $(2 \%)$. Their solution would be viscous necessitating the high injection pressures used (at least $10 \mathrm{kPa}$ or $100 \mathrm{~cm} \mathrm{H}_{2} \mathrm{O}$ ). Injection of a highly viscous solution at this unphysiological pressure appears likely to severely distort if not destroy small pulmonary arteries and arterioles. The assessment of the vessels in their work was predominantly on the study of radiographs. The only histology performed was the tracing of an axial pathway by serial section in which side branches were noted but not followed.

The conclusions we have reached are based on the measurement of pressures required to obtain free venous flow, and the measurement of particles able to pass through the pulmonary vascular bed. The histological observation of gelatin in the pulmonary veins confirms the findings seen during the injection. The resistance to tlow through these vessels will be several thousand times lower than that of a capillary (about 2000 for a diameter of $40 \mu \mathrm{m}$ and 10000 for a diameter of $60 \mu \mathrm{m}$ based on the resistance being proportional to $1 / \mathrm{r})^{4}$.

The origin of these shunting vessels is of interest. It has been suggested that in the developing fetus there is a 'deep circulation' of blood in the lung which bypasses the capillary bed (M Rosan, personal communication). Two origins can thus be proposed for the origin of these shunting vessels: firstly that they are the remnants of this hypothetical 'deep' fetal circulation, or that they are an abnormality of development. The difficulty experienced in tracing the vessels from artery to vein suggests that shunt vessels are dispersed widely throughout the lungs with perhaps one or two in each lobule.

In conclusion we have confirmed the suggestion of Lauweryns ( $M$ Rosan, personal communication) that there is a 'deep' direct arteriovenous pathway bypassing the alveolar capillary bed in the lung. In some infants, under ill defined conditions, sudden opening of these shunt vessels could produce a large and possibly life threatening intrapulmonary shunt. While we continue to study these vessels histologically, physiological studies will be required to isolate the events which control their opening.

We are indebted to HM Coroners of Nottingham and Lincoln for access to the material, and to the coroner's officers and many members of the constabularies for their detailed records of the incidents.

1 Southall DP, Talbert DG, Johnson P, et al. Prolonged expiratory apnoea: a disorder resulting in episodes of severe tory apnoea: a disorder resulting in episodes of severe arterial hypoxaen

2 Southall DP, Talbert DG, Johnson P, et al. Prolonged expiratory apnoea and hypoxaemia. Lancet 1985;ii:1125-6.

3 Southall DP, Samuels MP, Talbert DG. Recurrent cyanotic episodes with severe arterial hypoxaemia and intrapulmonary shunting: a mechanism for sudden death. Arch Dis Child (in press).

4 Hislop A, Reid L. Pulmonary arterial development during childhood, branching patterns and structure. Thorax 1973; 28:129-35.

5 Emery J. Unexpected death in infancy. In: Hull D, ed. Recent advances in paediatrics. Vol 5. London: Churchill Livingstone, 1976:203-20.

6 Dennison D. Where and how hypoxia works. In: Heath DA, ed. Aspects of hypoxia. Liverpool: Liverpool University Press, 1986:235-45. 